\title{
Comparison of the histological structure of the tibial nerve and its terminal branches in the fresh and fresh-frozen cadavers
}

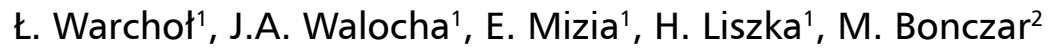 \\ 'Department of Anatomy, Jagiellonian University Medical College, Krakow, Poland \\ 2Intermed Medical Clinic, Zabierzow, Poland
}

[Received: 7 June 2020; Accepted: 28 July 2020; Early publication date: 7 August 2020]

Background: The aim of this study was to compare the histological structure (cross-sectional area [CSA] and number of nerve fascicles) of the distal part of the tibial nerve (TN) and its terminal branches (medial plantar nerve [MPN], lateral plantar nerve [LPN]) in the fresh and fresh-frozen cadavers using computer assisted image analysis.

Materials and methods: The TNs with terminal branches (MPN and LPN) were dissected from the fresh and fresh-frozen cadavers. Each nerve was harvested $5 \mathrm{~mm}$ proximally and respectively $5 \mathrm{~mm}$ distally from the TN bifurcation, marked, dehydrated, embedded in paraffin, sectioned at $2 \mu \mathrm{m}$ slices and stained with haematoxylin and eosin. Then the specimens were photographed and analysed using Olympus cellSens software.

Results: The fresh cadavers' group comprised 60 feet (mean age $68.1 \pm 15.2$ years). The mean CSA and the number of nerve fascicles were respectively $15.25 \pm 4.6 \mathrm{~mm}^{2}, 30.35 \pm 8.45$ for the TN, $8.76 \pm 1.93 \mathrm{~mm}^{2}, 20.75 \pm 7.04$ for the MPN and $6.54 \pm 2.02 \mathrm{~mm}^{2}, 13.40 \pm 5.22$ for the $L P N$. The fresh-frozen cadavers' group comprised 21 feet (mean age $75.1 \pm 9.0$ years). The mean CSA and the number of nerve fascicles were respectively $13.71 \pm 5.66 \mathrm{~mm}^{2}, 28.57 \pm 8.00$ for the TN, $7.55 \pm 3.25 \mathrm{~mm}^{2}, 18.00 \pm 6.72$ for the MPN and $4.29 \pm 1.93 \mathrm{~mm}^{2}$, $11.33 \pm 1.93$ for the LPN. Only LPNs showed statistical differences in the CSA and the number of nerve fascicles between examined groups $(p=0.000$, $p=0.037$, respectively). A positive correlation was found between donors age and tibial nerve CSA in the fresh cadavers group $(r=0.44, p=0.000)$. A statistical difference was found between the MPN and LPN both in the CSA and the number of nerve fascicles $(p<0.001, p<0.001$, respectively).

Conclusions: The CSA and the number of nerve fascicles of the tibial and medial plantar nerves were similar in the fresh and fresh-frozen cadavers whilst different in the LPN. The TN showed increasing CSA with the advanced age in the fresh cadavers. The MPN had larger CSA and more nerve fascicles than the LPN. (Folia Morphol 2021; 80, 3: 542-548)

Key words: tibial nerve, cross-sectional area, medial and lateral plantar nerves, fresh cadavers, fresh-frozen cadavers 


\section{INTRODUCTION}

The tibial nerve (TN) is a peripheral sensorimotor nerve arising as a branch of sciatic nerve bifurcation in the popliteal fossa [40]. It runs vertically on the tibialis posterior muscle together with the posterior tibial vessels. Postero-inferiorly to the medial malleolus it terminates emitting medial plantar nerve (MPN) and smaller lateral plantar nerve (LPN) [28]. The TN bifurcation level shows a great variability as so depending on the study its localisation is referred to the medial or lower located lateral malleolus [24, 43]. Most commonly it is described below the tip of the medial malleolus, inside the tarsal tunnel [42]. Tibial nerve and its branches provide innervation to the posterior lower leg, the muscles and skin of the sole of the foot [21].

For many years ankle arthroscopy has proved to be a useful diagnostic and therapeutic procedure for ankle and foot disorders. Although it is a minimally invasive surgery neurological complications are most frequently reported referring to the tibial, sural, superficial peroneal and deep peroneal nerves [1, 45, 47]. According to Freedman and Barron [13] all neurovascular impairments are caused by distractor pin or portal placement. In order to avoid iatrogenic injuries and to perform safe and reproducible arthroscopy constant training is highly recommended.

Nowadays necessity of constant practicing of surgical skills is emphasized by professionals [2]. They clearly highlight the superiority of fresh cadavers among any frozen or anatomically preserved. However, due to ethical and technical problems as well as limited access to the fresh bodies, fresh-frozen cadavers proved to be convenient surgical training model [35]. Because of their most lifelike features they are used by surgeons, orthopaedics, radiologists and anaesthesiologist to practice and improve operating skills $[12,17]$. Fresh-frozen bodies also found application in the research and bioengineering, allowing development of new instruments and procedures.

The aim of this study was to compare the histological structure of the TN and its terminal branches in the fresh and fresh-frozen cadavers.

\section{MATERIALS AND METHODS}

The study was conducted on 60 lower limbs of the fresh cadavers and on 21 lower limbs of the fresh-frozen cadavers in the Department of Anatomy between December 2016 and March 2019. The group of fresh-frozen cadavers composed of already ampu- tated lower limbs at the level of the knee originating from mixed donors with known medical record. The exclusion criteria were any deformation of the lower limb or the lower limb trauma, surgical or radiotherapeutic procedures of the lower limb, chronic disease of the lower limb in the medical record of the donor.

The research protocol was approved by the local Ethics Committee (Registry No. 122.6120.315.2016). The study has been performed in accordance with the ethical standards established in the 1964 Declaration of Helsinki and its later amendments.

\section{Dissection technique}

The incision was made in the midline between the tip of the medial malleolus and the Achilles tendon. It continued $10 \mathrm{~cm}$ proximally along the Achilles tendon and $10 \mathrm{~cm}$ distally curving anteriorly $2 \mathrm{~cm}$ below the tip of the medial malleolus. Upon dissecting the skin and the subcutaneous tissue the TN was visualised together with the posterior tibial artery and two posterior tibial veins. After meticulous dissection the TN, its bifurcation and LPN and MPN were exposed. The plantar nerves were marked $2 \mathrm{~cm}$ distally from the TN bifurcation point with the following pattern: blue thread - lateral plantar nerve, white thread - medial plantar nerve. The TN was left without any marking. Then $3 \mathrm{~cm}$ proximally to the bifurcation the TN was cut out from the main nerve trunk. Accordingly, $3 \mathrm{~cm}$ distally the MPN and LPN were cut out. The excised tibial nerve and its terminal branches were removed en bloc from the cadaver. The incision was closed with the running subcuticular suture. In the group of fresh-frozen cadavers the dissection was performed after thawing of the specimens overnight at room temperature. The harvesting was carried out by the same surgeon.

\section{Preparation of histological slide}

The excised block of nerves was fixed in a $10 \%$ solution of the formaldehyde ( $\mathrm{pH}$ 7.4). After 2-5 days it was removed from the formaldehyde. The TN was cut transverse to the nerve axis $5 \mathrm{~mm}$ and $10 \mathrm{~mm}$ proximally to the TN bifurcation point as were the MPN and LPN $5 \mathrm{~mm}$ and $10 \mathrm{~mm}$ distally to the TN bifurcation point. Obtained $5 \mathrm{~mm}$ long nerve fragments were dehydrated separately and embedded in paraffin according to its initial marking. Each paraffin cube was transverse sectioned with the microtome providing one $2 \mu \mathrm{m}$ thick slice. Subsequently each slice was stained with haematoxylin and eosin (Fig. 1). 


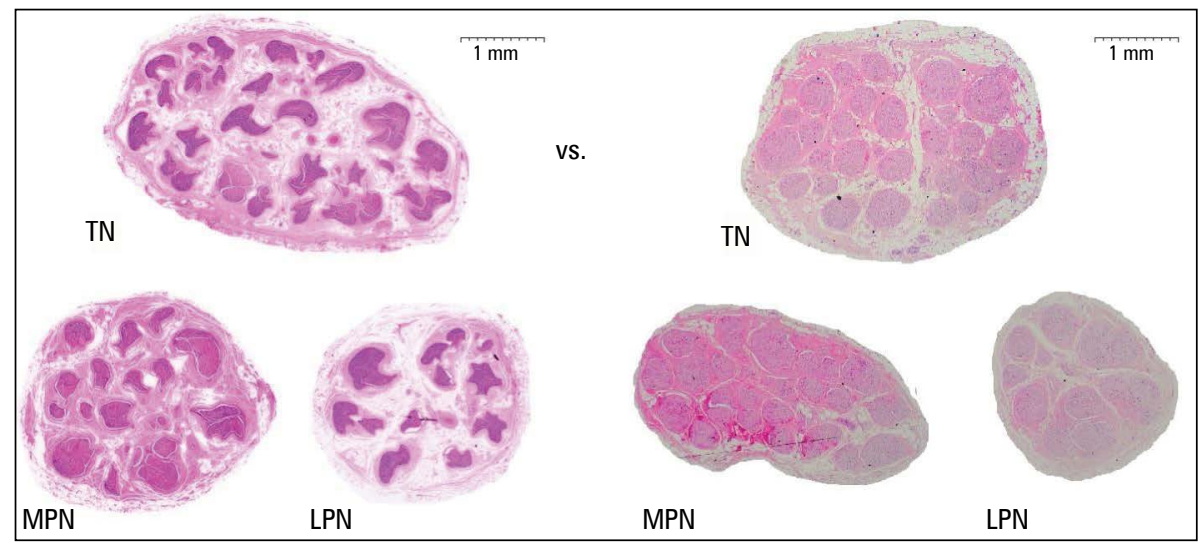

Figure 1. Cross-section of tibial nerve (TN), medial plantar nerve (MPN) and lateral plantar nerve (LPN) of the fresh cadaver (on the left) and fresh-frozen cadaver (on the right). Haematoxylin and eosin staining.

Table 1. Measured nerve parameters for tibial nerve, medial plantar nerve, and lateral plantar nerve — comparison between fresh and fresh-frozen cadavers

\begin{tabular}{|c|c|c|c|c|c|c|c|c|c|c|c|c|}
\hline \multicolumn{2}{|c|}{ Measurement } & \multicolumn{5}{|c|}{ Fresh cadavers } & \multicolumn{5}{|c|}{ Fresh-frozen cadavers } & \multirow[t]{2}{*}{$\mathbf{P}$} \\
\hline & & $\mathbf{N}$ & Mean \pm SD & Median & $\begin{array}{l}\text { Lower } \\
\text { quartile } \\
\text { (01) }\end{array}$ & $\begin{array}{c}\text { Upper } \\
\text { quartile } \\
(03)\end{array}$ & $\mathbf{N}$ & Mean \pm SD & Median & $\begin{array}{l}\text { Lower } \\
\text { quartile } \\
\text { (01) }\end{array}$ & $\begin{array}{c}\text { Upper } \\
\text { quartile } \\
(03)\end{array}$ & \\
\hline \multirow{3}{*}{$\begin{array}{l}\text { Cross-sec- } \\
\text { tional area } \\
{\left[\mathrm{mm}^{2}\right]}\end{array}$} & Tibial nerve & 60 & $15.25 \pm 4.65$ & 14.66 & 11.77 & 17.29 & 21 & $13.71 \pm 5.66$ & 12.84 & 9.50 & 16.15 & 0.094 \\
\hline & Medial $p$ & 60 & 8 & 8.45 & 7. & 9.90 & 21 & 3.25 & 7.53 & 4.61 & 10.36 & 0.156 \\
\hline & Lateral plantar nerve & 60 & $6.54 \pm 2.02$ & 6.44 & 5.12 & 7.41 & 21 & $4.29 \pm 1.93$ & 4.31 & 2.52 & 5.76 & 0.000 \\
\hline \multirow{3}{*}{$\begin{array}{l}\text { Number } \\
\text { of nerve } \\
\text { fascicles }\end{array}$} & Tibial nerve & 60 & $30.35 \pm 8.45$ & 31.00 & 25.00 & 35.25 & 21 & $28.57 \pm 8.00$ & 31.00 & 22.00 & 35.00 & 0.403 \\
\hline & Medial plantar nerve & 60 & $20.75 \pm 7.04$ & 20.00 & 16.00 & 25.00 & 21 & $18.00 \pm 6.72$ & 18.00 & 12.00 & 22.00 & 0.123 \\
\hline & Lateral plantar nerve & 60 & $13.40 \pm 5.22$ & 13.50 & 10.75 & 15.00 & 21 & $11.33 \pm 1.93$ & 11.00 & 7.00 & 14.00 & 0.037 \\
\hline
\end{tabular}

Numbers in bold indicate statistically significant differences between fresh and fresh-frozen cadavers $(p<0.05)$; SD — standard deviation

\section{Micromorphometry}

The cross-sectional area (CSA) and the number of nerve fascicles of the TN, MPN, and LPN were assessed using a light microscope (Olympus BX53, 20× magnification). Each cross-section was photographed (20X magnification), afterwards the CSA was measured semi-automatically using Olympus cellsens Standard 2.3 software with the producer's precision of $10 \mu \mathrm{m}$, whilst the number of nerve fascicles was calculated manually. Each slice was assessed once by the same pathologist. Then the values of the CSA and the number of nerve fascicles were tabulated according to the group (fresh or fresh-frozen cadavers).

\section{Statistical analysis}

Obtained data were statistically processed using descriptive statistics such as percentage, mean, median, standard deviation, upper and lower quartiles. A p-value of $<0.05$ was considered as statistically significant. Two groups were compared using the Mann-Whitney test or t-test depending on normal distribution. To compare CSA and number of nerve fascicles between TN, MPN and LPN paired t-test or Wilcoxon rang test were used depending on whether data was normally distributed. Correlation coefficients were calculated to establish any statistical dependence between parameters. All analyses were performed using MedCalc version 16.8.

\section{RESULTS}

There were 30 fresh cadavers dissected $(n=60$ lower limbs) with a mean age of $68.1 \pm 15.2$ (range from 27 to 91 years). 28 (46.7\%) feet were female and $32(53.3 \%)$ were male. In the group of fresh-frozen cadavers 21 lower limbs were dissected with a mean age of $75.1 \pm 9.0$ (range from 60 to 92 years). Twelve (57.1\%) feet were female and $9(42.9 \%)$ were male. The mean CSA and number of nerve fascicles of the TN, MPN, and LPN in the fresh and fresh-frozen groups are presented in Table 1. Gender differences between examined groups are presented in Table 2 . In both examined groups males' tibial nerves showed larger CSA and more nerve fascicles than females'. Only LPNs showed statistical differences in the CSA 
Table 2. Measured nerve parameters for tibial nerve, medial plantar nerve, and lateral plantar nerve - comparison by gender between fresh and fresh-frozen cadavers

\begin{tabular}{|c|c|c|c|c|c|c|c|c|c|c|c|c|c|}
\hline \multirow[t]{2}{*}{ Gender } & \multirow{2}{*}{\multicolumn{2}{|c|}{ Measurement }} & \multicolumn{5}{|c|}{ Fresh cadavers } & \multicolumn{5}{|c|}{ Fresh-frozen cadavers } & \multirow[t]{2}{*}{$\mathbf{p}$} \\
\hline & & & $\mathbf{N}$ & $\begin{array}{l}\text { Mean } \\
\pm \text { SD }\end{array}$ & Median & $\begin{array}{l}\text { Lower } \\
\text { quartile } \\
\text { (01) }\end{array}$ & $\begin{array}{c}\text { Upper } \\
\text { quartile } \\
\text { (03) }\end{array}$ & $\mathbf{N}$ & $\begin{array}{l}\text { Mean } \\
\pm S D\end{array}$ & Median & $\begin{array}{c}\text { Lower } \\
\text { quartile } \\
\text { (01) }\end{array}$ & $\begin{array}{c}\text { Upper } \\
\text { quartile } \\
(03)\end{array}$ & \\
\hline \multirow[t]{6}{*}{ Women } & \multirow{3}{*}{$\begin{array}{l}\text { Cross-sec- } \\
\text { tional area } \\
{\left[\mathrm{mm}^{2}\right]}\end{array}$} & Tibial nerve & 28 & $\begin{array}{c}12.27 \\
\pm 2.45\end{array}$ & 11.85 & 10.35 & 14.31 & 12 & $\begin{array}{c}12.70 \\
\pm 3.90\end{array}$ & 13.46 & 9.28 & 15.27 & 0.802 \\
\hline & & Medial plantar nerve & 28 & $\begin{array}{c}7.81 \\
\pm 1.41\end{array}$ & 7.37 & 6.70 & 9.10 & 12 & $\begin{array}{c}7.77 \\
\pm 3.38\end{array}$ & 7.41 & 5.88 & 10.78 & 0.988 \\
\hline & & Lateral plantar nerve & 28 & $\begin{array}{c}5.83 \\
\pm 1.25\end{array}$ & 5.77 & 4.61 & 6.86 & 12 & $\begin{array}{c}4.47 \\
\pm 2.05\end{array}$ & 4.56 & 2.70 & 5.79 & 0.030 \\
\hline & \multirow{3}{*}{$\begin{array}{l}\text { Number } \\
\text { of nerve } \\
\text { fascicles }\end{array}$} & Tibial nerve & 28 & $\begin{array}{c}26.32 \\
\pm 8.87\end{array}$ & 25.00 & 19.50 & 34.00 & 12 & $\begin{array}{c}28.08 \\
\pm 9.13\end{array}$ & 31.50 & 20.50 & 34.25 & 0.555 \\
\hline & & Medial plantar nerve & 28 & $\begin{array}{c}17.71 \\
\pm 5.28\end{array}$ & 18.00 & 14.50 & 20.50 & 12 & $\begin{array}{c}16.50 \\
\pm 7.23\end{array}$ & 17.00 & 12.00 & 19.75 & 0.426 \\
\hline & & Lateral plantar nerve & 28 & $\begin{array}{c}11.50 \\
\pm 3.72\end{array}$ & 12.00 & 9.00 & 14.00 & 12 & $\begin{array}{c}11.42 \\
\pm 7.23\end{array}$ & 9.00 & 6.00 & 14.25 & 0.417 \\
\hline \multirow[t]{6}{*}{ Men } & \multirow{3}{*}{$\begin{array}{l}\text { Cross-sec- } \\
\text { tional area } \\
{\left[\mathrm{mm}^{2}\right]}\end{array}$} & Tibial nerve & 32 & $\begin{array}{c}17.86 \\
\pm 4.57\end{array}$ & 17.10 & 15.02 & 19.90 & 9 & $\begin{array}{c}15.06 \\
\pm 7.45\end{array}$ & 12.57 & 10.09 & 16.29 & 0.053 \\
\hline & & Medial plantar nerve & 32 & $\begin{array}{c}9.58 \\
\pm 1.95\end{array}$ & 9.16 & 8.40 & 10.66 & 9 & $\begin{array}{c}7.26 \\
\pm 3.25\end{array}$ & 7.64 & 4.61 & 9.83 & 0.092 \\
\hline & & Lateral plantar nerve & 32 & $\begin{array}{c}7.17 \\
\pm 2.36\end{array}$ & 7.08 & 5.18 & 8.35 & 9 & $\begin{array}{c}4.05 \\
\pm 1.86\end{array}$ & 3.35 & 2.28 & 5.66 & 0.001 \\
\hline & \multirow{3}{*}{$\begin{array}{l}\text { Number } \\
\text { of nerve } \\
\text { fascicles }\end{array}$} & Tibial nerve & 32 & $\begin{array}{r}33.88 \\
\pm 6.31\end{array}$ & 34.00 & 28.50 & 38.00 & 9 & $\begin{array}{c}29.22 \\
\pm 6.67\end{array}$ & 30.00 & 25.00 & 35.00 & 0.119 \\
\hline & & Medial plantar nerve & 32 & $\begin{array}{c}23.41 \\
\pm 7.37\end{array}$ & 22.50 & 17.50 & 29.50 & 9 & $\begin{array}{c}20.00 \\
\pm 5.77\end{array}$ & 20.00 & 17.00 & 24.00 & 0.270 \\
\hline & & Lateral plantar nerve & 32 & $\begin{array}{c}15.06 \\
\pm 5.81\end{array}$ & 14.50 & 12.50 & 16.50 & 9 & $\begin{array}{c}11.22 \\
\pm 2.73\end{array}$ & 12.00 & 9.00 & 13.00 & 0.020 \\
\hline
\end{tabular}

Numbers in bold indicate statistically significant differences between males and females $(p<0.05)$; SD — standard deviation

and number of nerve fascicles between examined groups. The LPN also proved statistical difference among males (CSA and number of nerve fascicles) and females (CSA) in fresh and fresh-frozen cadavers. In the fresh cadavers no statistically significant differences between right and left foot of the individual were found $(p>0.05)$. Such comparison was not possible to perform in the fresh-frozen cadavers as the examined lower limbs originated from different individuals. There is statistically significant difference between MPN and LPN in CSA and number of nerve fascicles in both groups $(p<0.001)$. CSA of the MPN confirmed to be 1.3 times and 1.8 times larger than the lateral plantar nerves' in the fresh and fresh-frozen specimens, respectively. The MPN also proved to have more nerve fascicles than the LPN in both examined groups. A positive correlation was noted between the age of donors and the CSA of the TN in the fresh cadavers group $(r=0.44, p=0.000$; Table 3).

\section{DISCUSSION}

The present study compares histological structure (CSA and number of nerve fascicles) of the distal part of the TN and its terminal branches (MPN and LPN) in the fresh and fresh-frozen cadavers assessed using computer-assisted measurements. Literature analysis shows that in the previous studies the CSA of the tibial nerve was evaluated by ultrasound or magnetic resonance imagining on the living patients or volunteers $[5,15,22]$. To the best of our knowledge this is the first publication analysing histological differences in peripheral nerves obtained from the fresh and fresh-frozen cadavers. It is also the first study revealing TN, MPN, and LPN CSA measured directly on the nerves harvested from the fresh cadavers. Furthermore no reference values for the CSA of the medial and lateral plantar are available in the literature.

In the present study the TN, MPN, and LPN harvested from the 60 fresh cadavers were compared to 21 collected from the fresh-frozen cadavers. The fresh 
Table 3. Association between age and measured nerve parameters for tibial nerve, medial plantar nerve, and lateral plantar nerve in fresh and fresh-frozen cadavers

\begin{tabular}{|c|c|c|c|c|c|c|c|}
\hline \multirow[t]{2}{*}{ Measurement } & & \multicolumn{3}{|c|}{ Fresh cadavers } & \multicolumn{3}{|c|}{ Fresh-frozen cadavers } \\
\hline & & $\mathbf{N}$ & $\mathbf{R}$ & $\mathbf{P}$ & $\mathbf{N}$ & $\mathbf{R}$ & $\mathbf{P}$ \\
\hline \multirow[t]{3}{*}{ Cross-sectional area $\left[\mathrm{mm}^{2}\right]$} & Tibial nerve & 60 & 0.439 & 0.000 & 21 & 0.112 & 0.629 \\
\hline & Medial plantar nerve & 60 & 0.083 & 0.531 & 21 & 0.040 & 0.862 \\
\hline & Lateral plantar nerve & 60 & 0.110 & 0.401 & 21 & -0.045 & 0.847 \\
\hline \multirow[t]{3}{*}{ Number of nerve fascicles } & Tibial nerve & 60 & 0.086 & 0.512 & 21 & -0.161 & 0.485 \\
\hline & Medial plantar nerve & 60 & -0.224 & 0.085 & 21 & -0.140 & 0.545 \\
\hline & Lateral plantar nerve & 60 & -0.104 & 0.428 & 21 & -0.204 & 0.376 \\
\hline
\end{tabular}

Numbers in bold indicate statistically significant age correlation $(p<0.05)$.

Table 4. Studies of the tibial nerve cross-sectional area (CSA) measured at the level of medial malleolus

\begin{tabular}{|c|c|c|c|c|c|}
\hline & Group (n) & Mean age & $\begin{array}{l}\text { CSA of the tibial nerve at the level } \\
\text { of medial malleolus [mm²] }\end{array}$ & $\begin{array}{c}\text { Reference range } \\
{\left[\mathrm{mm}^{2}\right]}\end{array}$ & Type of study \\
\hline He et al., 2019 [16] & 40 & 55.2 & $11.6 \pm 1.6$ & - & US 4-15 MHz \\
\hline Lothet et. al., 2019 [25] & 15 & 21.7 & 12.3 & - & US $18 \mathrm{MHz}$ \\
\hline Bedewi et al., 2018 [5] & 138 & 38.3 & $12.7 \pm 4.5$ & $2.0-30.0$ & US $18.5 \mathrm{MHz}$ \\
\hline Grimm et al., 2018 [15] & 100 & 51.2 & $10.2 \pm 2.0$ & - & US $14 \mathrm{MHz}$ \\
\hline Kronlage et al., 2017 [22] & 60 & 30.5 & $8.1 \pm 2.0^{*}$ & $4.0-12.1$ & MRI \\
\hline Singh et al., 2017 [36] & 75 & 39.5 & $12.4 \pm 1.1$ & $10.0-14.0$ & US 7-18 MHz \\
\hline Kang et al., 2016 [20] & 20 & 65.0 & $12.4 \pm 2.9$ & - & US 7-12 MHz \\
\hline Boehm et al., 2014 [7] & 56 & 50.2 & $9.6 \pm 2.2$ & $9.0-10.2$ & US $12-15 \mathrm{MHz}$ \\
\hline Seok et al., 2014 [33] & 94 & 43.9 & $12.1 \pm 3.1$ & $8.5-22.8$ & US 5-12 MHz \\
\hline Riazi et al., 2012 [31] & 43 & 46.8 & $17.7 \pm 6.5$ & - & US $6-13 \mathrm{MHz}$ \\
\hline Tagliafico et al., 2012 [38] & 58 & 47.0 & $9.6 \pm 4.0$ & $7.2-13.7$ & US $17.5 \mathrm{MHz}$ \\
\hline Cartwright et al., 2008 [11] & 60 & 45.9 & $13.7 \pm 4.3$ & $5.1-22.3$ & US $15 \mathrm{MHz}$ \\
\hline Lee et al., 2005 [23] & 24 & 57.4 & 12.0 & - & US $10-12 \mathrm{MHz}$ \\
\hline
\end{tabular}

*Measured at the proximal third of the calf; MRI — magnetic resonance imaging; US — ultrasonography

cadavers group composed of younger donors (mean age: 68.1 vs 75.1) and presented slightly higher values of CSA (TN: 15.25 vs. 13.71 ; MPN: 8.76 vs. 7.55 ; LPN: 6.54 vs. 4.29 ) and more nerve fascicles (TN: 30.35 vs. 28.57; MPN: 20.75 vs. 18.00 ; LPN: 13.40 vs. 11.33 ). Nevertheless tibial nerve CSA measured in both groups is in line with results of ultrasound and magnetic resonance imaging performed on living patients (Table 4). The statistical analysis proved that the tibial and medial plantar nerves are similar in the fresh and fresh-frozen groups. On the other hand the lateral plantar nerves appeared to be statistically different. Such discrepancy may be the result of anatomical differences of the examined nerves. The LPN is the smaller terminal branch of the TN bifurcation [21]. Because of that it may be suggested that freezing process does not alter larger nerves (TN, MPN) whilst impacts smaller ones (LPN). Although the differences proved to be statistically insignificant (except for LPN) their slightly decreased values in fresh-frozen cadavers is worth noticing. Besides micromorphometric assessment some differences between two examined groups appeared during its histological preparation. Fresh-frozen specimens showed grater stiffness and hardness of the nerve trunks, poorly stained with haematoxylin and eosin and revealed more artefacts in the microscopic analysis.

Decreased CSA of the assessed nerves may be explained by Bakhach [4] who described changes occurring in biological tissues during freezing using thermodynamic and biophysical laws. Emphasizing that water may reach up to $70 \%$ of tissues volume he examined its transfer between intra and extracellular compartments throughout crystallisation process. Intracellular formation and aggregation of ice crystals destroy its structures and cause mechanical stress on the cell walls resulting in deformation and fragmentation. Moreover 
water transition into a solid state leads to changes in extracellular chemical composition with the increased ion accumulation. Such concentration gradient between cell membrane makes water run out of the intracellular space causing its dehydration. These may elucidate rigidness of the nerve samples, artefacts in the microscopic assessment and slightly decreased CSA of the fresh-frozen cadavers registered in the present study.

Although fresh cadavers retain biomechanical features and are most suitable for the surgical training, they putrefy and are available only for the short time [3] . Searching for the best fresh body equivalent brought to many studies on its preservation [9, 12]. Along with proved advantages each method revealed some limitations, as so: formalin fixation makes the specimens stiff and discoloured, Thiel embalming requires infrastructure for the process and is not suitable for all tissues, fresh-freezing brings the risk of infection and needs time for thawing [39]. Nevertheless, fresh-frozen cadavers seem to be the most flexible and realistic [19]. They appeared to be even better than the virtual reality stimulator [34].

While literature provides comparative analysis of the fresh and fresh-frozen tendons $[6,18]$, bones [10, 26, 41], and osteochondral allografts, [29] there is lack of such comparison for the human peripheral nerves. Hohmann et al. [18] revealed that the long head of biceps tendons showed higher loads to failure and lower elasticity in the fresh-frozen samples when compared to the fresh specimens. At the same time fresh tendons were wider and presented larger CSA. On the contrary, Bitar et al. [6] state that fresh-frozen tendons of the semitendinosus muscle show no histological differences referring to the fresh ones. Similarly Panjabi et al. [30] deny any physical or histological changes in the fresh-frozen specimens. Opposite to that, Giannini et al. [14] noted an increased CSA in the fresh-frozen tendons of the posterior tibial muscles as well as increased stiffness and decreased ultimate load. An interesting study was performed by Zarb et al. [46] who analysed the quality of the magnetic resonance images of living patients', fresh-frozen and Thiel embalmed bones, ligaments, tendons and muscles of the ankle. The image quality of the fresh-frozen specimen appeared to be higher when compared to that of living patient. Unfortunately no nerves of the ankle were included in the research which might have been beneficial for the present study reference.

Fresh-frozen peripheral nerves were examined mostly in relation to their biomechanical properties $[8,44]$.
Stouthandel et al. [37] compared Thiel embalmed and fresh-frozen median nerves showing slight increase of CSA in the embalmed group, no significant difference in elasticity and similar biomechanical patterns. Enlarged CSA of the nerves preserved with the Thiel method is interpreted to be the result of the embalming fluid uptake. Sargon et al. [32] counted the myelinated nerve fibres of the fresh-frozen facial nerve terminal branches concluding that both fresh and fresh-frozen human specimens are better than formalin-fixed in order to perform the anatomic dissection and find tiny nerves.

To the best of our knowledge there has not been any publication which compared histological structure of the fresh-frozen human nerves to the fresh ones. As so, such analysis of the peripheral nerves together with biomechanical experiments may constitute a valuable subject for the future studies.

Albeit there were relatively high number of lower limbs examined in the present study (81 feet) their uneven distribution among the compared groups (60 vs. 21) and low number of fresh-frozen cadavers might have influenced the results. Only 9 males in the fresh-frozen cadavers group would have significantly hindered the gender comparison. Second limitation is the fact that lower limbs included in the group of fresh-frozen cadavers originated from different donors which impeded the intra-individual left-right comparison. Another restriction is the various age of the analysed groups which is proved to correlate with peripheral nerves CSA [15, 27]. Narrow range of age in the fresh-frozen cadavers (from 60 to 92 years) might have also biased the age correlation which was confirmed for the tibial nerve CSA in the fresh cadavers (range of age from 27 to 91 years). Therefore, for the sake of future studies, the authors would recommend to collect and compare specimens from the contralateral sides of the individual (followed by the left-right difference exclusion).

\section{CONCLUSIONS}

To conclude, the authors of the present study proved that freezing process alters tissue properties of the smaller nerves on top of impacting biomechanical features of the peripheral nerves. Histological structure of the larger nerves remains uninfluenced by the freezing process.

\section{Conflict of interest: None declared}

\section{REFERENCES}

1. Abdul-Jabar HB, Bhamra J, Quick TJ, et al. latrogenic posterior tibial nerve division during a combined anterior ankle arthroscopy with 
an additional posterolateral portal. J Surg Case Rep. 2016; 2016(5): rjw097, doi: 10.1093/jscr/rjw097, indexed in Pubmed: 27197613.

2. András C, Josvai A, Gergely C, et al. The importance of daily fast fresh cadaver dissection (how can we organize it?). J Neurol Stroke. 2019; 9(1), doi: 10.15406/jnsk.2019.09.00336.

3. Arnout N, Myncke J, Vanlauwe J, et al. The influence of freezing on the tensile strength of tendon grafts : a biomechanical study. Acta Orthop Belg. 2013; 79(4): 435-443, indexed in Pubmed: 24205775.

4. Bakhach J. The cryopreservation of composite tissues. Organogenesis. 2014; 5(3): 119-126, doi: 10.4161/org.5.3.9583.

5. Bedewi MA, Abodonya A, Kotb M, et al. Estimation of ultrasound reference values for the lower limb peripheral nerves in adults: A cross-sectional study. Medicine (Baltimore). 2018; 97(12): e0179, doi: 10.1097/MD.0000000000010179, indexed in Pubmed: 29561431.

6. Bitar AC, Santos LA, Croci AT, et al. Histological study of fresh versus frozen semitendinous muscle tendon allografts. Clinics (Sao Paulo). 2010; 65(3): 297-303, doi: 10.1590/S1807-59322010000300010, indexed in Pubmed: 20360921.

7. Boehm J, Scheidl E, Bereczki D, et al. High-resolution ultrasonography of peripheral nerves: measurements on 14 nerve segments in 56 healthy subjects and reliability assessments. Ultraschall Med. 2014; 35(5): 459-467, doi: 10.1055/s-0033-1356385, indexed in Pubmed: 24764211.

8. Botero SS, Honecker S, Jmal H, et al. The biomechanical properties of 44 human digital collateral nerves from fresh frozen cadavers. J Cell Immunother. 2018; 4(1): 38-40, doi: 10.1016/j.jocit.2018.09.009.

9. Brenner E. Human body preservation - old and new techniques J Anat. 2014; 224(3): 316-344, doi: 10.1111/joa.12160, indexed in Pubmed: 24438435.

10. Cartner JL, Hartsell ZM, Ricci WM, et al. Can we trust ex vivo mechanical testing of fresh--frozen cadaveric specimens? The effect of postfreezing delays. J Orthop Trauma. 2011; 25(8): 459-461, doi: 10.1097/BOT.0b013e318225b875, indexed in Pubmed: 21738060.

11. Cartwright MS, Passmore LV, Yoon JS, et al. Cross-sectional area reference values for nerve ultrasonography. Muscle Nerve. 2008; 37(5): 566-571, doi: 10.1002/mus.21009, indexed in Pubmed: 18351581.

12. Eisma R, Wilkinson T. From "silent teachers" to models. PLoS Biol. 2014; 12(10): e1001971, doi: 10.1371/journal.pbio.1001971, indexed in Pubmed: 25333490.

13. Freedman DM, Barron OA. latrogenic posterior tibial nerve division during ankle arthroscopy. Arthroscopy. 1998; 14(7): 769-772, doi: 10.1016/s0749-8063(98)70109-4, indexed in Pubmed: 9788378.

14. Giannini S, Buda R, Di Caprio F, et al. Effects of freezing on the biomechanical and structural properties of human posterior tibial tendons. Int Orthop. 2008; 32(2): 145-151, doi: 10.1007/s00264-006-0297-2, indexed in Pubmed: 17216243.

15. Grimm A, Axer $H$, Heiling $B$, et al. Nerve ultrasound normal values - Readjustment of the ultrasound pattern sum score UPSS. Clin Neurophysiol. 2018; 129(7): 1403-1409, doi: 10.1016/j. clinph.2018.03.036, indexed in Pubmed: 29729596.

16. He $\mathrm{Y}, \mathrm{Xiang} \mathrm{Xi}$, Zhu BH, et al. Shear wave elastography evaluation of the median and tibial nerve in diabetic peripheral neuropathy. Quant Imaging Med Surg. 2019; 9(2): 273-282, doi: 10.21037/ qims.2019.02.05, indexed in Pubmed: 30976551.

17. Hocking $G$, Mclntyre $O$. Achieving change in practice by using unembalmed cadavers to teach ultrasound-guided regional anaesthesia. Ultrasound. 2010; 19(1): 31-35, doi: 10.1258/ult.2010.010040.

18. Hohmann E, Keough N, Glatt V, et al. The mechanical properties of fresh versus fresh/frozen and preserved (Thiel and Formalin) long head of biceps tendons: A cadaveric investigation. Ann Anat. 2019; 221: 186-191, doi: 10.1016/j.aanat.2018.05.002, indexed in Pubmed: 29879483

19. Jansen $S$, Kirk $D$, Tuppin $K$, et al. Fresh frozen cadavers in surgical teaching: a gelatine arterial infusion technique. ANZ J Surg. 2011; 81(12): 880-882, doi: 10.1111/j.1445-2197.2010.05596.x, indexed in Pubmed: 22507413.

20. Kang S, Kim SeH, Yang SN, et al. Sonographic features of peripheral nerves at multiple sites in patients with diabetic polyneuropathy. J Diabetes Complications. 2016; 30(3): 518-523, doi: 10.1016/j. jdiacomp.2015.12.008, indexed in Pubmed: 26782023.

21. Koo GB, Lee JH, Jang JH, et al. Superficial course of the medial plantar nerve: case report. Anat Cell Biol. 2019; 52(1): 87-89, doi: 10.5115/ acb.2019.52.1.87, indexed in Pubmed: 30984458.

22. Kronlage M, Schwehr V, Schwarz D, et al. Magnetic resonance neurography : normal values and demographic determinants of nerve caliber and T2 relaxometry in 60 healthy individuals. Clin Neuroradiol. 2019; 29(1): 19-26, doi: 10.1007/s00062-017-0633-5, indexed in Pubmed: 29030674

23. Lee $D$, Dauphinée $D$. Morphological and functional changes in the diabetic peripheral nerve. J Am Podiatr Med Assoc. 2005; 95(5): 433-437, doi: 10.7547/0950433.

24. Lijoi F, Lughi M, Baccarani G. Posterior arthroscopic approach to the ankle: an anatomic study. Arthroscopy. 2003; 19(1): 62-67, doi: 10.1053/jars.2003.50003, indexed in Pubmed: 12522404.
25. Lothet EH, Bishop TJ, Walker FO, et al. Ultrasound-Derived nerve cross-sectional area in extremes of height and weight. J Neuroimaging. 2019; 29(3): 406-409, doi: 10.1111/jon.12590, indexed in Pubmed: 30582247.

26. Marieswaran M, Mansoori N, Digge VK, et al. Effect of preservation methods on tensile properties of human femur-ACL-tibial complex (FATC) - a cadaveric study on male subjects. Acta Bioeng Biomech. 2018; 20(4): 31-42.

27. Mizia E, Tomaszewski KA, Rutowicz B, et al. Computer-assisted assessment of the histological structure of the human sural nerve. Folia Morphol. 2014; 73(3): 292-297, doi: 10.5603/FM.2014.0046, indexed in Pubmed: 25242156.

28. Moore KL. Clinically Oriented Anatomy. 8th Edition, LWW 2017.

29. Pallante-Kichura AL, Chen AC, Temple-Wong MM, et al. In vivo efficacy of fresh versus frozen osteochondral allografts in the goat at 6 months is associated with PRG4 secretion. J Orthop Res. 2013; 31(6): 880-886, doi: 10.1002/jor.22319, indexed in Pubmed: 23362152.

30. Panjabi MM, Krag M, Summers D, et al. Biomechanical time-tolerance of fresh cadaveric human spine specimens. J Orthop Res. 1985; 3(3): 292-300 doi: 10.1002/jor.1100030305, indexed in Pubmed: 4032102.

31. Riazi S, Bril V, Perkins BA, et al. Can ultrasound of the tibial nerve detect diabetic peripheral neuropathy? A cross-sectional study. Diabetes Care. 2012; 35(12): 2575-2579, doi: 10.2337/dc12-0739, indexed in Pubmed: 23033242.

32. Sargon MF, Ogretmenoglu O, Gunenc Beser C, et al. Quantitative analysis of the terminal branches of facial nerve in fresh frozen head and neck specimens. Folia Morphol. 2014; 73(1): 24-29, doi: 10.5603/ FM. 2014.0004, indexed in Pubmed: 24590519.

33. Seok HY, Jang JH, Won SJ, et al. Cross-sectional area reference values of nerves in the lower extremities using ultrasonography. Muscle Nerve. 2014; 50(4): 564-570, doi: 10.1002/mus.24209, indexed in Pubmed: 24639103

34. Sharma M, Horgan A. Comparison of fresh-frozen cadaver and high-fidelity virtual reality simulator as methods of laparoscopic training. World J Surg. 2012; 36(8): 1732-1737, doi: 10.1007/s00268-0121564-6, indexed in Pubmed: 22484566.

35. Sharma M, Macafee D, Pranesh N, et al. Construct validity of fresh frozen human cadaver as a training model in minimal access surgery. JSLS. 2012; 16(3): 345-352, doi: 10.4293/108680812X1346288273 5818, indexed in Pubmed: 23318058

36. Singh K, Gupta K, Kaur S. High resolution ultrasonography of the tibial nerve in diabetic peripheral neuropathy. J Ultrason. 2017; 17(71): 246-252, doi: 10.15557/JoU.2017.0036, indexed in Pubmed: 29375899.

37. Stouthandel MEJ, Vanhove C, Devriendt W, et al. Biomechanical comparison of Thiel embalmed and fresh frozen nerve tissue. Anat Sci Int. 2020; 95(3): 399-407, doi: 10.1007/s12565-020-00535-1, indexed in Pubmed: 32144646

38. Tagliafico A, Cadoni A, Fisci E, et al. Reliability of side-to-side ultrasound cross-sectional area measurements of lower extremity nerves in healthy subjects. Muscle Nerve. 2012; 46(5): 717-722, doi: 10.1002/ mus.23417, indexed in Pubmed: 23055313.

39. Thiel W. [The preservation of the whole corpse with natural color]. Ann Anat. 1992; 174(3): 185-195, indexed in Pubmed: 1503236.

40. Tomaszewski KA, Graves MJ, Henry BM, et al. Surgical anatomy of the sciatic nerve: A meta-analysis. J Orthop Res. 2016; 34(10): 1820-1827. doi: 10.1002/jor.23186, indexed in Pubmed: 26856540.

41. Unger S, Blauth M, Schmoelz W, et al. Effects of three different preservation methods on the mechanical properties of human and bovine cortical bone. Bone. 2010; 47(6): 1048-1053, doi: 10.1016/j. bone.2010.08.012, indexed in Pubmed: 20736094.

42. Warchol $Ł$, Walocha JA, Mizia $E$, et al. Ultrasound-guided topographic anatomy of the medial calcaneal branches of the tibial nerve. Folia Morphol. 2021; 80(2): 267-274, doi: 10.5603/FM.a2020.0062, indexed in Pubmed: 32488855.

43. Warchoł $t$, Mróz I, Mizia $E$, et al. Vascular density of inferior tibiofibular joint - cadaveric experimental study. Folia Med Cracov. 2017; 57(1): 47-54, indexed in Pubmed: 28608862.

44. Wong YR, Pang $X$, Lim ZY, et al. Biomechanical evaluation of peripheral nerves after crush injuries. Heliyon. 2019; 5(4): e01557, doi: 10.1016/j. heliyon.2019.e01557, indexed in Pubmed: 31183426.

45. Young BH, Flanigan RM, DiGiovanni BF. Complications of ankle arthroscopy utilizing a contemporary noninvasive distraction technique. J Bone Joint Surg Am. 2011; 93(10): 963-968, doi: 10.2106/ JBJS.I.00977, indexed in Pubmed: 21593373.

46. Zarb F, McNulty J, Gatt A, et al. Comparison of in vivo vs. frozen vs. Thiel cadaver specimens in visualisation of anatomical structures of the ankle on proton density Magnetic Resonance Imaging (MRI) through a visual grading analysis (VGA) study. Radiography (Lond). 2017: 23(2): 117-124, doi: 10.1016/j.radi.2016.12.004, indexed in Pubmed: 28390542.

47. Zengerink $M$, van Dijk CN, Zengerink $M$, et al. Complications in ankle arthroscopy. Knee Surg Sports Traumatol Arthrosc. 2012; 20(8): 1420-1431, doi: 10.1007/s00167-012-2063-x, indexed in Pubmed: 22669362. 